\title{
Microwave Assisted Synthesis of Guar Gum Grafted Acrylic Acid/Nanoclay Superabsorbent Composites and Its Use in Crystal Violet Dye Absorption
}

\author{
S. B. Shruthi' ${ }^{1}$ Chandan Bhat ${ }^{1}$, S. P. Bhaskar ${ }^{1}$, G. Preethi ${ }^{1}$, R. R. N. Sailaja ${ }^{2 *}$ \\ ${ }^{1}$ Chemical Engineering Department, Dayananda Sagar College of Engineering, Kumaraswamy Layout, Bengaluru, \\ India \\ ${ }^{2}$ Resource Efficient Process Technology Application, The Energy and Resources Institute, \\ Bengaluru, India \\ Email: "sailajab@teri.res.in
}

Received 23 December 2015; accepted 15 February 2016; published 18 February 2016

Copyright (C) 2016 by authors and Scientific Research Publishing Inc.

This work is licensed under the Creative Commons Attribution International License (CC BY).

http://creativecommons.org/licenses/by/4.0/

(c) () Open Access

\begin{abstract}
Natural gums can be tailored and used for the removal of toxic dyes like crystal violet via grafting techniques. However, grafting via microwave irradiation showed both higher yield and fast reaction kinetics as compared to conventional grafting. Silane modified nanoclay has been used to prepare acrylic acid grafted guar gum nanocomposites via microwave irradiation technique. The grafting was confirmed via infra-red spectroscopy while XRD diffractograms suggested exfoliation of modified nanoclay in guar gum grafted acrylic acid. The reaction kinetic parameters have been optimized. The effect of nanoclay on swelling characteristics has been examined. The sensitivity of pH on swelling capabilities has also been assessed. The efficiency of the superabsorbent nanocomposite on the absorption of crystal violet dye has been studied. The superabsorbent nanocomposite loaded with $\mathbf{1 . 7 5 \%}$ modified nanocaly was found to be optimal concentration for the removal of crystal violet dye.
\end{abstract}

\section{Keywords}

Microwave, Guar Gum, Superabsorbent, Nanocomposites, Dye Absorption

\section{Introduction}

Superabsorbents are three dimensional networks with a capacity to absorb and retain large quantities of water.

"Corresponding author.

How to cite this paper: Shruthi, S.B., Bhat, C., Bhaskar, S.P., Preethi, G. and Sailaja, R.R.N. (2016) Microwave Assisted Synthesis of Guar Gum Grafted Acrylic Acid/Nanoclay Superabsorbent Composites and Its Use in Crystal Violet Dye Absorption. Green and Sustainable Chemistry, 6, 11-25. http://dx.doi.org/10.4236/gsc.2016.61002 
The water absorbency is facilitated by various functional groups such as amine, hydroxyl, amide and carboxyl groups. The loosely crosslinked networks are made up of homopolymers or grafted copolymers which can hold water [1]. Superabsorbents are used for a wide variety of applications. Further, depleting petrochemical resources prompts us to look for benign and sustainable alternatives. Thus, plant and animals based renewable resources such as starch, cellulose, chitosan various gums etc. have been widely studied. Although biopolymeric materials are abundantly available, sustainable, environment friendly, they have inferior properties as compared to synthetic polymers. Hence, they have to be modified for various applications. Thus, grafted polysaccharides have been synthesized and used for various drug delivery applications [1]-[4].

Grafted chitosan has been covalently immobilized on enzyme for biosensor applications [5]. Gums such as Xanthan gum, Arabic gum, Acacia gum etc. are abundantly available. Most of these gums are commonly used as thickening, stabilizing, binding and emulsifying agents. They are mainly classified based on their ionic nature and origin. Guar gum is a plant based hydrocolloid and an edible polysaccharide and is extracted from cyamopsistetragonoloba [6]. It mainly consists of galactomannans with $(1,4)-$ linked-B-D-mannopyranose units [7]. It is a high molecular weight carbohydrate polymer which swells in cold water. Hence, it is widely used as a thickener emulsifier in food, cosmetics and pharmaceutical industries. Gum based materials modified by grafting crosslinking irradiation are attractive for agricultural applications as reviewed by Guiclherme et al. [8]. An improved moisture retention capacity for acrylic-acid-aniline grafted gum hydrogels has been synthesized by Sharma et al. [9]. Similar observations that have been made by Sharma et al. for grafted gum exhibited both water retention as well as dye removal properties [10]. Grafted gums with electrical conductivity applications have also been synthesized [11]. Similar usage of guar gum for sensor based applications has been developed by Dharela et al. [12]. Various researchers have also used gums for drug delivery applications such as for antibiotics. Interpenetrating networks for controlled release of amoxicillin trihydrateexibhited Fickian diffusion characteristics [2] [3]. Guar gum showed potential for tablet coating, carriers for drug release as reviewed by Prabaharan [13]. Thus, as seen in all these applications, modification via grafting leads to development of products which can be tailored to get tunable properties.

Microwave assisted grafting is a convenient approach with rapid reaction rates and higher yields. Singh et al. [14] [15] synthesized and characterized methylated starch and cassia marginata gum grafted acrylonitrile via microwave irradiation. Modified gum showed enhanced thermal stability as observed by Singh et al. [16]. Review articles by Singh et al. [17] and Sosnik et al. [18] highlight the importance of microwave irradiation for polysaccharide modification although upscaling to produce large quantities is still being developed. Similar studies on the modification of guar gum by grafting sodium acrylate and montmorillonite have been carried out by Wang et al. to study the swelling characteristics and $\mathrm{pH}$ sensitivity [19]. Recently studies on superabsorbent composites in combination with clay nanocomposites led to improvement in swelling and adsorption characteristics as observed by Kabiri et al. [20]. However, studies on grafted guar gum loaded with nanofiller superabsorbent nanocomposites for dye removal applications are very few. Yan et al. [21] used carbon nanotubes along with modified guar gum for the removal of neutral red and methylene blue dyes. Hybrid nanocomposites comprised of Xanthan gum loaded with nanosilica particles led to enhanced absorption ability for the removal of Cango red dye [22]. Similar observations have also been made for guar gum/nanosilica composite for the removal of reactive blue and Congo red dyes [20]. In this study, crystal violet dye has been chosen as it is hazardous in nature. Hence, in this study guar gum along with silane modified nanoclay has been grafted with acrylic acid via microwave irradiation technique. The various kinetic parameters have been optimized. The synthesized super absorbent nanocomposite has been investigated for crystal violet dye removal.

\section{Experimental}

\subsection{Materials}

Nanoclay (Montmorillonite clay surface modified with 15 - $35 \mathrm{wt} \%$ octadecylamine and 0.5 - $5 \mathrm{wt} \%$ aminopropyltriethoxysilane) was purchased from Sigma Aldrich, USA. Guar gum with molecular weight $4.22 \times 10^{6}$, Ammonium persulphate (Extrapure), NN'-Methylene bis-acrylamide has been procured from SD Fine-Chem Limited, Mumbai. Methyl Violet (10 B, practical grade) was obtained from Himedia Laboratories Pvt. Ltd. Mumbai. All the other solvents and chemicals of analytical grade were purchased from SD Fine-Chem Limited, Mumbai.

\subsection{Synthesis of Control ( $0 \%$ NC) Sample}

$1 \mathrm{~g}$ of guar gum is dissolved in $100 \mathrm{ml}$ of distilled water. $6 \mathrm{ml}$ of acrylic acid is added to the guar gum solution 
and stirred for 10 minutes. $0.09 \mathrm{~g}$ of ammonium persulphate (APS) initiator and $0.09 \mathrm{~g}$ of methylene bisacrylamide (MBA) cross linker was added to the mixture. Then it was subjected to microwave irradiation using locally fabricated Microwave reactor (Enerzi Microwave Systems, India) at different temperatures and varied reaction times. To carry out the reaction power of $800 \mathrm{~W}$ was supplied. The reaction mixture of acrylic acid grafted guar gum was cooled to room temperature. In order to remove unreacted acrylic acid and homopolymer, the mixture was neutralized using $1 \mathrm{~N} \mathrm{NaOH}$ till the $\mathrm{pH}$ reaches 7 . This was followed by precipitation using acetone. The precipitate obtained was washed several times with acetone and kept for drying at $80^{\circ} \mathrm{C}$ for 5 - 6 hours.

\subsection{Synthesis of Superabsorbent/Nanoclay Composites}

The procedure for synthesis of superabsorbent with nanoclay is similar to that of control sample with sonication. Varied quantities of nanoclay was added to guar gum solution and sonicated for 30 minutes. After sonication, acrylic acid, MBA and APS were added. Similar process of microwave irradiation was carried out and the dried composite of superabsorbent with nanoclay was obtained. Amount of nanoclay was varied from 0 to $5 \mathrm{wt} \%$.

\subsection{Optimization of Reaction Parameters}

The reaction parameters i.e., monomer concentration, initiator dosage, cross-linker concentration, nanoclay concentration, time of reaction and temperature of the reaction has been optimized to obtain the maximum grafting percentage. The effects of these reaction parameters on the percentage swelling were investigated.

\subsection{Swelling Kinetics}

$0.1 \pm 0.01 \mathrm{~g}$ of powdered superabsorbent was taken in a test tube and $10 \mathrm{ml}$ of prepared buffer solution was added. For every interval of 10 minutes the solution was decanted using filter paper. The weight of swollen sample was noted. The procedure was repeated till 120 minutes. Equilibrium swelling of sample was calculated using Equation (1).

$$
\text { Equilibrium Swelling in }(g / g)=\frac{\left(W_{s}-W_{d}\right)}{W_{d}}
$$

where, $W_{s}$ = weight of swollen sample (g);

$W_{d}=$ weight of dried sample (g).

\subsection{Dye Removal Studies}

Dye adsorption was carried out by immersing the $0.05 \pm 0.01 \mathrm{~g}$ of grafted guar gum into $20 \mathrm{ml}$ of dye solution. All adsorption experiments were examined through a batch method. To study the adsorption kinetics, at specified time intervals, the amount of adsorbed crystal violet dye was evaluated using a UV spectrometer at $\lambda_{\max }=$ $590 \mathrm{~nm}$ [23]. Adsorption capacity ( $\mathrm{q}_{\mathrm{t}}, \mathrm{mg} / \mathrm{g}$ ) is calculated using following Equation 2 given below. Similar procedure was carried out for the composite with optimal concentration of nanoclay. Standard dye solution of crystal violet dye was prepared for five different concentrations namely $10 \mathrm{mg} / \mathrm{l}, 20 \mathrm{mg} / \mathrm{l}, 30 \mathrm{mg} / \mathrm{l}, 40 \mathrm{mg} / \mathrm{l}$ and 50 $\mathrm{mg} / \mathrm{l}$. The absorbance of dye solution was measured using UV spectrometer at a wavelength of $590 \mathrm{~nm}$.

$$
\text { Adsorption capacity, } \mathrm{q}_{t}=\frac{\left(C_{o}-C_{t}\right)}{m} \times V
$$

where,

$C_{o}$ is the initial dye concentration (mg/l);

$C_{t}$ is the remaining dye concentrations in the solution at time $\mathrm{t}(\mathrm{mg} / \mathrm{l})$;

$V$ is the volume of dye solution used (l);

$m$ is the weight of superabsorbent (mg).

\subsection{Fourier Transform Infrared Spectroscopy}

The Fourier transform infrared spectroscopy (FTIR) analysis of pure guar gum, pure nanoclay and guar gum grafted acrylic acid were carried out using FTIR spectrophotometer (Perkin-Elmer spectrum 1000) between 300 
and $4000 \mathrm{~cm}^{-1}$. The samples were coated on a potassium bromide $(\mathrm{KBr})$ plate and dried in a vacuum oven at $120^{\circ} \mathrm{C}$ before it was tested.

\subsection{X-Ray Diffraction Studies}

X-ray diffraction (XRD) measurements for the composites have been performed using advanced diffractometer (analytical, XPERT-PRO) equipped with $\mathrm{Cu}-\mathrm{K} \alpha$ radiation source $(\mathrm{X}=0.154 \mathrm{~nm})$. The diffraction data were collected in the range of $2 \theta=3^{\circ}-60^{\circ}$ using a fixed time mode with a step interval of $0.05^{\circ}$.

\subsection{Thermogravimetric Analysis (TGA)}

The TGA of guar gum and acrylic acid grafted guar gum nanocomposite were carried out by using Perkin-Elmer Pyris Diamond 6000 analyzer in an atmosphere of nitrogen. The sample was subjected to a heating rate of $10^{\circ} \mathrm{C}$ $/ \mathrm{min}$ in a heating range of $20^{\circ} \mathrm{C}-900^{\circ} \mathrm{C}$.

\subsection{Scanning Electron Microscope (SEM)}

The morphological characterization of the specimen was carried out using a scanning electron microscope (SEM) (JEOL, JSM-840A microscope). The specimens were gold sputtered prior to microscopy.

\subsection{Transmission Electron Microscopy (TEM)}

Transmission electron microscopy (TEM) for nanocomposites has been performed using a JEOL, Model 782, operating at $200 \mathrm{kV}$. TEM specimens were prepared by dispersing the composite powders in methanol by ultrasonication. A drop of the suspension was put on a TEM support grid (300 mesh copper grid coated with carbon). After drying in air, the composite powder remained attachedto the grid and was viewed under the transmission electron microscope.

\section{Results and Discussion}

\subsection{Fourier Transform Infrared Spectroscopy}

Figure 1 shows FTIR spectrograms of neat guar gum and acrylic acid guar gum. Neat guar gum (curve a) shows characteristic bands at 3430 and $2945 \mathrm{~cm}^{-1}$ for $-\mathrm{O}-\mathrm{H}$ stretching vibration along with $-\mathrm{C}-\mathrm{H}$ stretching. The bands at 1468 and $1098 \mathrm{~cm}^{-1}$ corresponds to $-\mathrm{C}-\mathrm{H}$ and $-\mathrm{O}-\mathrm{H}$ bending vibrations [24]. A new band at $1584 \mathrm{~cm}^{-1}$ can be seen for guar gum grafted acrylic acid (curve b) indicating formation of ester group and the presence of carboxylic anion [25].

\subsection{Morphology}

Figure 2(a) and Figure 2(b) show the SEM micrographs of grafted guar gum (without nanoclay) and guar gum-g-acrylic acid loaded with 1.75\% nanoclay respectively. The grafted guar gum (without nanoclay) shows a smooth but dense surface. The nanocomposite exhibits a coarse dimpled surface indicating dispersion of nanoclay in the matrix. Similar observation has been made by Wang et al. [19]. Rough surfaces lead to enhancement of overall surface area and hence increased the adsorption sites [26] [27]. TEM images of 1.75\% NC loaded guar gum are shown in Figure 2(b) and Figure 2(c). TEM images show clusters of various sizes. This agglomeration has been caused during TEM grid preparation due to drying induced clustering [28] [29]. Hence, the presence of uniformly spread both large and small aggregates can be seen. Similar observations have been made by Liu et al. [27] and Giri et al. [28]. Due to intercalation of the nanoclay particles, the interlayer space increased due to which, the water absorbency improved [30]-[32].

\subsection{XRD Analysis}

XRD diffractograms for the nanocomposite is shown in Figure 3. In the case of guar gum grafted acrylic acid (without i.e. $0 \%$ nanoclay); the peaks appear at $2 \theta$ values of $5.2^{\circ}$ and $19.77^{\circ}$ respectively. The nanoclay used has crystalline peaks at $2 \theta$ values of $7.8^{\circ}, 19.73^{\circ}, 24.17^{\circ}, 26.63^{\circ}$ and $34.98^{\circ}$. For the nanocomposite loaded with $1.75 \%$ NC, the peaks both in the lower as well as higher range are not to be seen. This indicates that the silane modified 


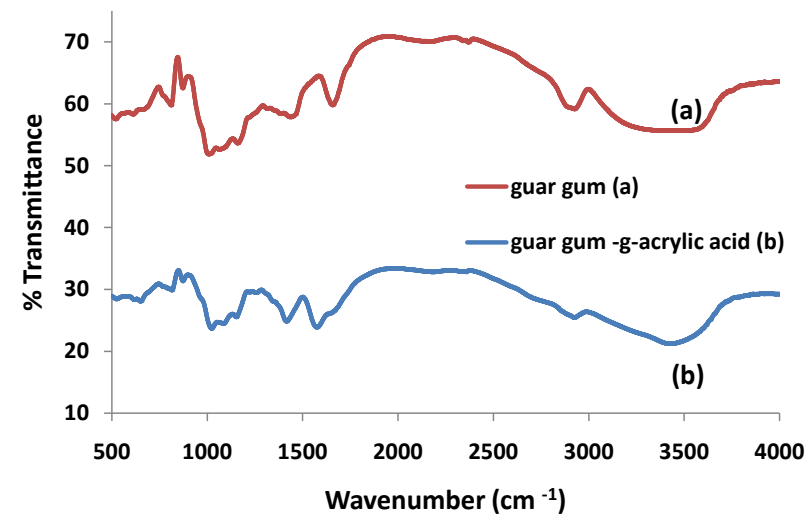

Figure 1. FTIR spectrograms of neat guar gum and acrylic acid guar gum.
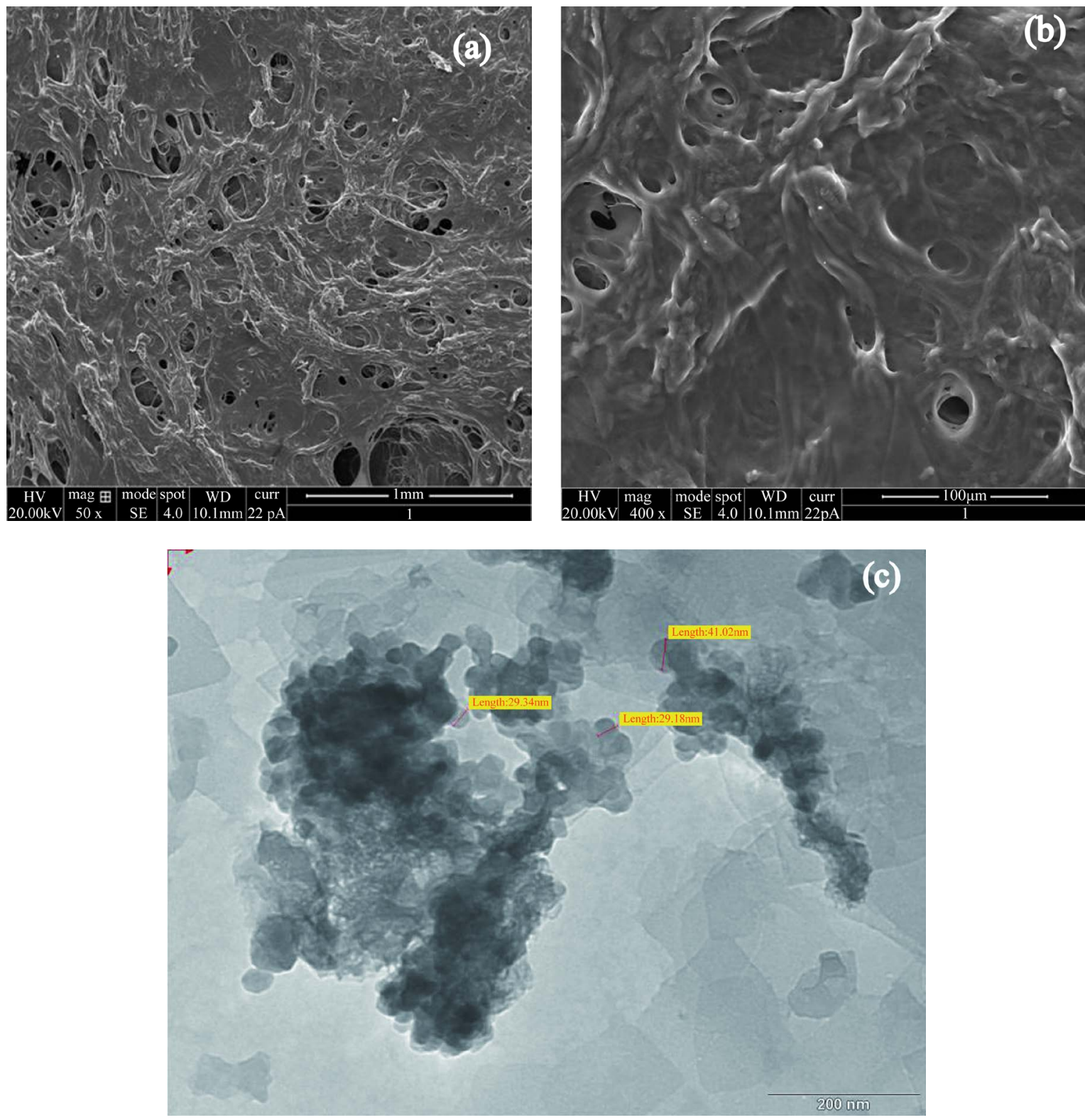


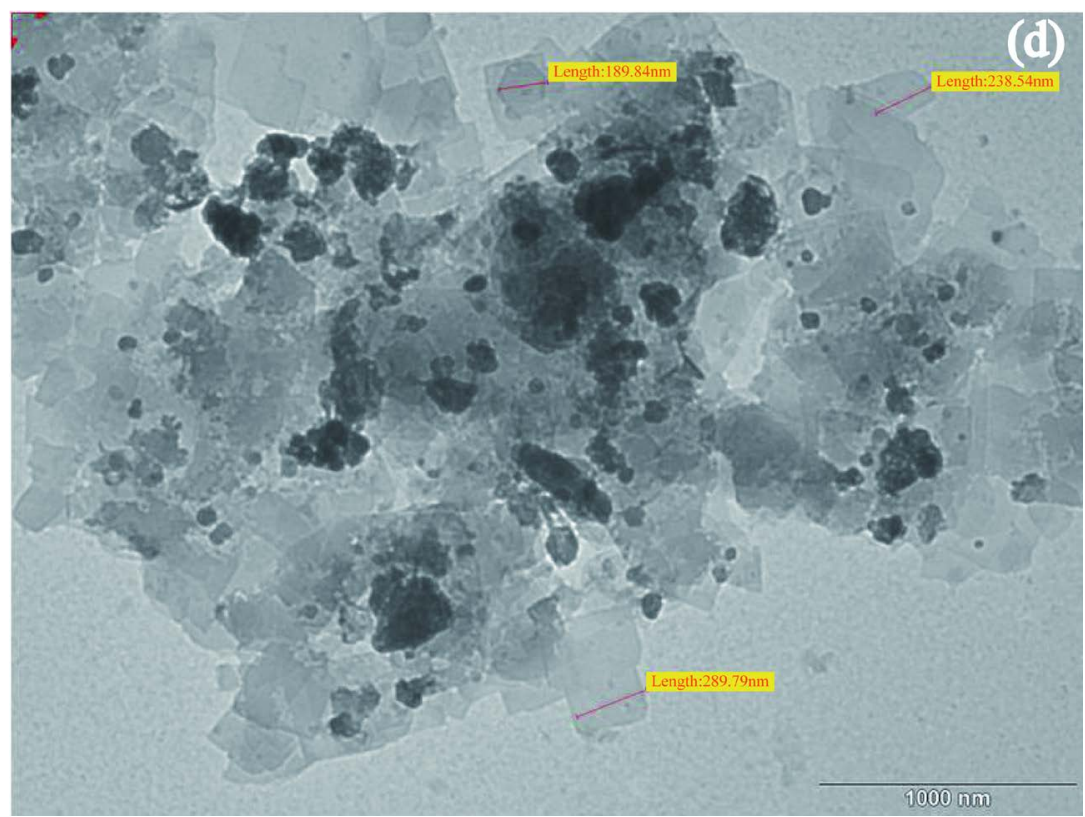

Figure 2. SEM micrographs of (a) without i.e. $0 \% \mathrm{NC}$ and (b) with $1.75 \% \mathrm{NC}$ and TEM images of composite loaded with $1.75 \%$ NC ((c) and (d)).
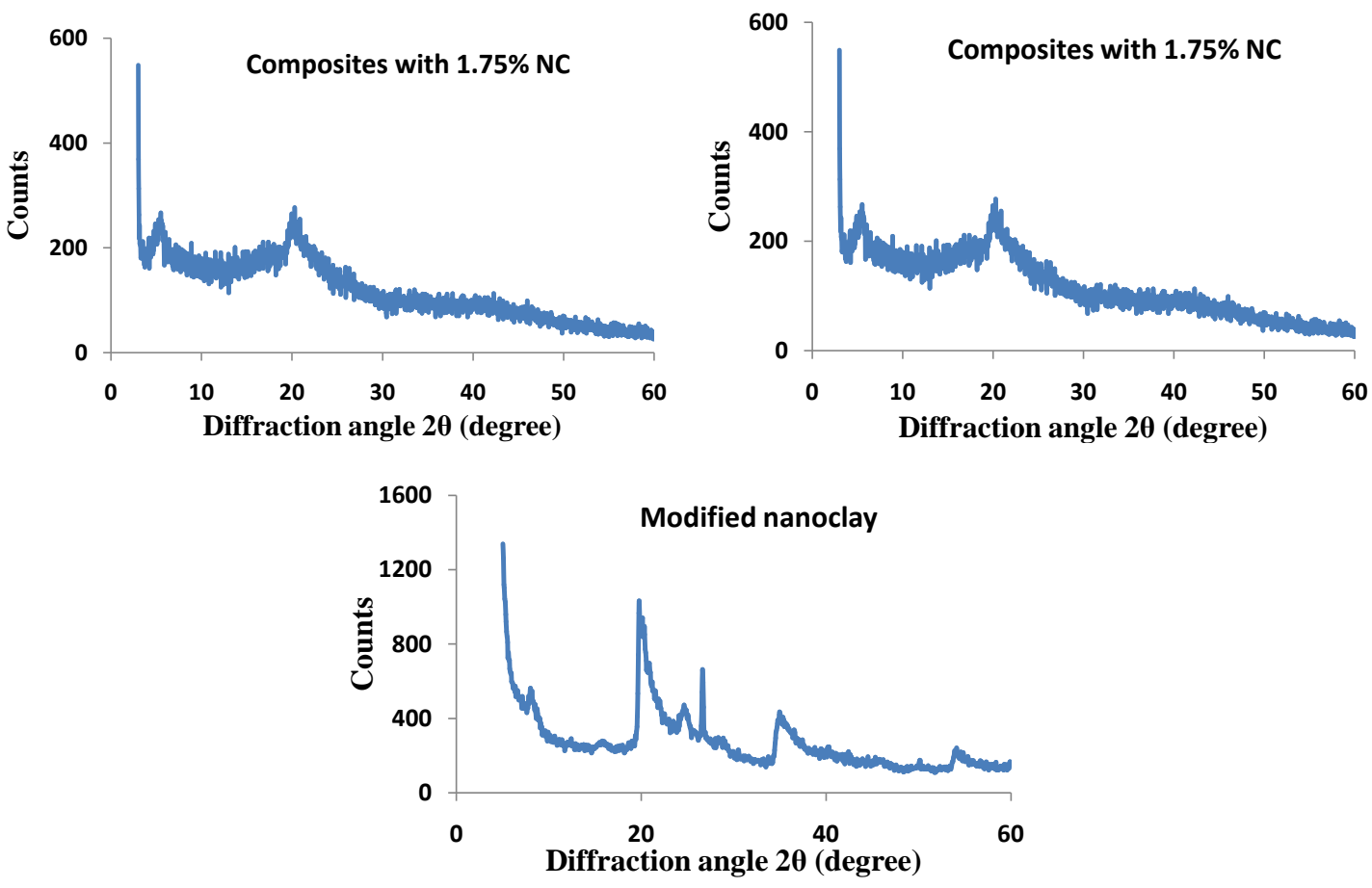

Figure 3. XRD diffractograms of nanocomposites.

nanoclay has exfoliated in grafted guar gum. The amine groups of silane modified nanoclay can interact effectively with the carboxyl and unsubstituted hydroxyl groups of grafted guar gum.

\subsection{Thermogravimetric Analysis}

The TGA thermograms of neat guar gum and the nanocomposite loaded with 1.75\% NC is shown in Figure 4. The initial mass loss for neat guar gum is due to removal of absorbed water. The first zone of weight loss of 


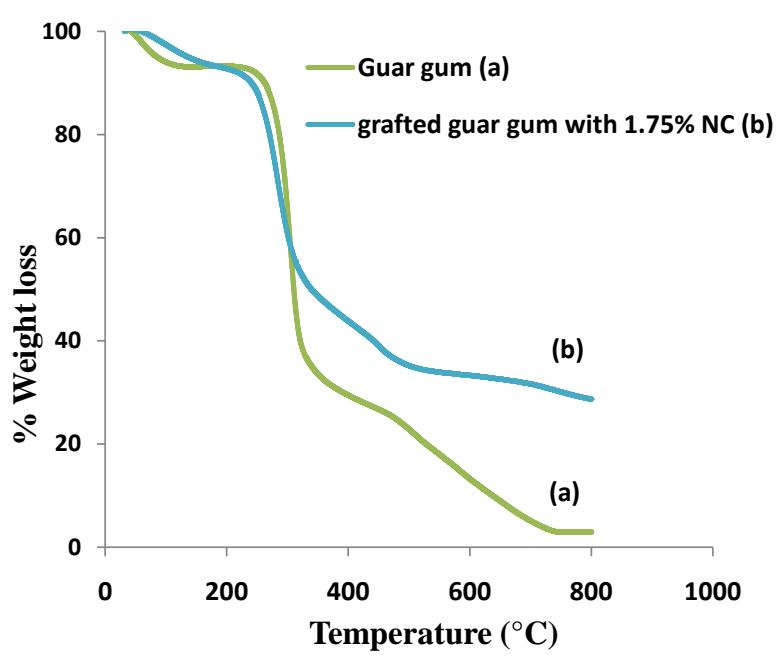

Figure 4. TGA thermograms of neat guar gum (a) and grafted guar gum loaded with $1.75 \%$ NC (b).

$10 \%$ occurs at $260.3^{\circ} \mathrm{C}$ due to the onset of decomposition of guar gum. The second major zone with $63 \%$ weight loss starts at $328.4^{\circ} \mathrm{C}$ due to cleavage of guar gum backbone [20]. For the nanocomposite loaded with $1.75 \%$ NC, $63 \%$ weight loss occurs at $436^{\circ} \mathrm{C}$ indicating enhanced thermal stability due to the presence of ceramic nanoparticles. The initial decrease in decomposition temperature for grafted guar gum is due to anhydride decomposition which forms due to dehydration of acrylic acid [33] [34].

\subsection{Optimization of Reaction Parameters}

The influence of monomer (acrylic acid) concentration has been studied by synthesizing series of composites with varied quantities of acrylic acid. Volume of acrylic acid has been varied from $2 \mathrm{ml}$ to $8 \mathrm{ml}$, Figure 5(a) indicates that addition of $6 \mathrm{ml}$ of acrylic acid gives maximum grafting percentage of $9 \%$, and thereafter it reduces. Co-polymerization between acrylic acid and guar gum increases the grafting percentage thereafter it decreases due to formation of homopolymer of acrylic acid. Similar observation has been reported by Bardajee et al. [35] for salep grafted sodium acrylate/alumina based superabsorbent.

Initiator has greater influence on rate of polymerization as it involves in initiating free radicals. Figure 5(b) depicts that continuous increase in grafting percentage upto $25 \%$ is observed till an optimum weight of $90 \mathrm{mg}$ which indicates that initiation of free radicals increases the polymerization which in turn increases the grafting percentage. At higher levels of initiator concentration, grafting is unfavorable and this behavior is attributed to the formation of excess number of free radical sites leading to shorter polymer chains. Yu et al. [36] analyzed that in case of carboxymethyl chitosan/vinyl monomer superabsorbent with Azobis (isobutyl amide hydrochloride) as initiator, the mean kinetic chain length decreased with increase in initiator concentration.

Concentration of crosslinker has considerable effects on water absorbency. In Figure 5(c) it is observed that highest Equilibrium swelling of $6.96 \mathrm{~g} / \mathrm{g}$ is achieved at $90 \mathrm{mg}$ of MBA, thereafter it is decreases. This behavior indicates that initially crosslinker forms a continuous three-dimensional network which facilitates water to penetrate into polymer network space. Higher crosslinker concentration leads to increased number of crosslink points and crosslink density, due to which network space for water retention is reduced. Similar observation has been reported by Wang et al. [37] in case of guar gum/attalpulgite based superabsorbent with methylene bisacrylamide as crosslinker.

Reaction time is the deciding factor for efficiency of reaction. Series of nanocomposites at time interval of 0 to 6 minutes has been synthesized. From Figure 5(d), it can be seen that the maximum grafting percentage of 14\% has been observed at reaction time of 4 minutes thereafter it decreases gradually. This behavior is attributed to increase of co-polymerization at initial intervals of reaction time which favors increase in grafting percentage. However, at higher reaction times (after 4 minutes) formation of short chain polymers is favorable which decreases the grafting percentage. Similar observations are reported in the study carried out by Likitha et al. [38].

Figure 5(e) shows the effect of temperature on grafting percentage. From figure it can be seen that as the 

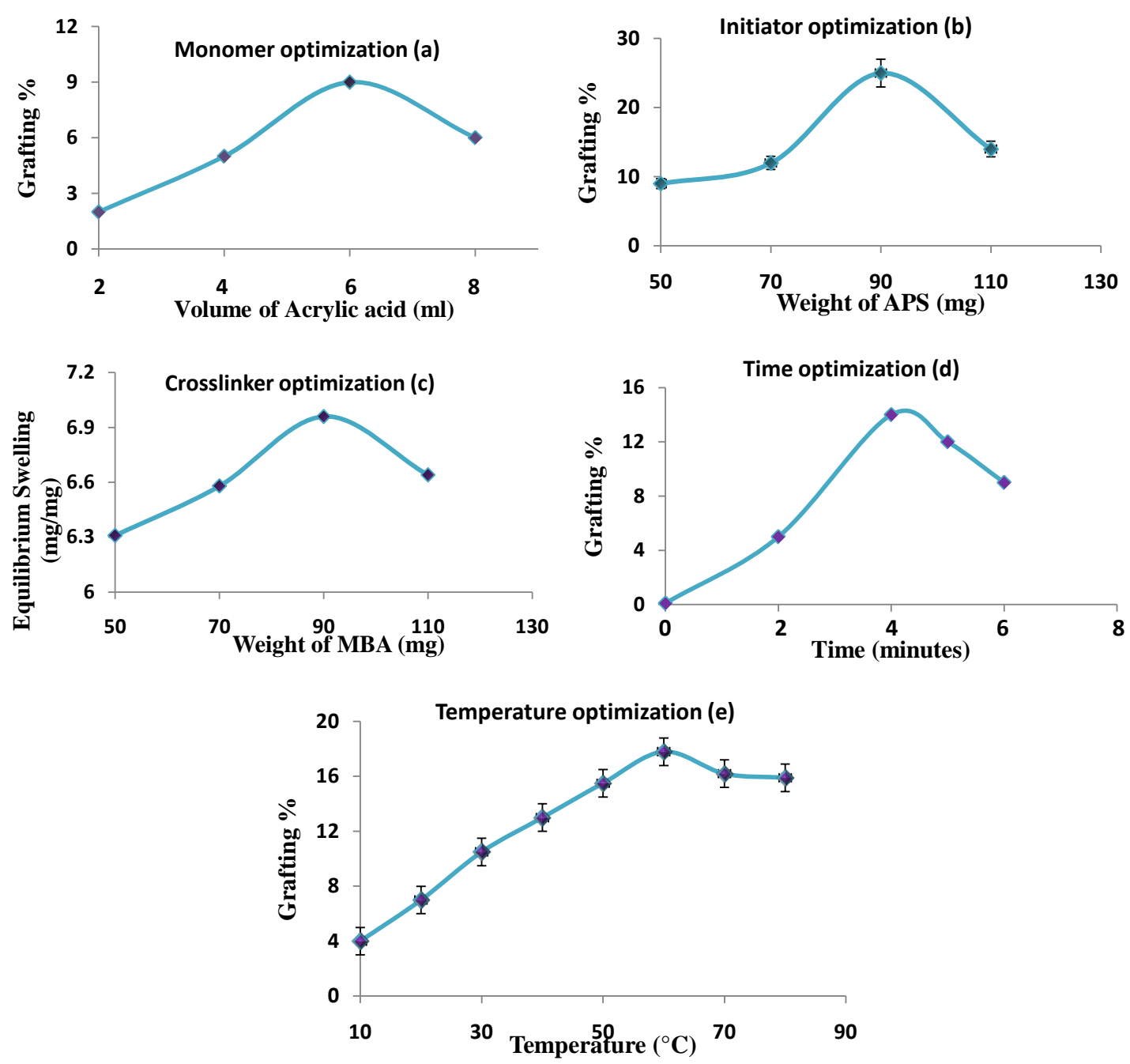

Figure 5. Variation of grafting percentage with (a) monomer concentration, (b) initiator concentration, (c) crosslinker concentration, (d) reaction time and (e) reaction temperature.

temperature increased grafting percentage also increased till $60^{\circ} \mathrm{C}$ then it has decreased slightly. This behavior indicates that a temperature of $60^{\circ} \mathrm{C}$ is desirable for radical formation thereafter excess radical's forms short chain polymers leading to decreased grafting percentage.

\subsection{Effect of Nanoclay on Water Absorbency Characteristics (Optimization of Nanoclay Percentage)}

The water absorbency increases with increased nanoclay content upto 1.75\% (Figure 6). Further nanoclay loading led to a decrease in equilibrium swelling value. The initial increase in absorbency may be due to inhibition of entanglement of grafted polymer chains due to the addition of rigid nanoclay particles. Further, the hydrophilic groups i.e. $-\mathrm{OH}$ and $-\mathrm{COOH}$ weakened the hydrogen bonding interactions which allow penetration of water. At higher nanoclay contents, the voids would be filled and increase the hydrophobicity leading to reduction in swelling properties. Similar observations on polysaccharide based superabsorbent nanocomposites have been made by Zhang et al. [39] and Wang et al. [32].

\subsection{Effect of PH Medium on Equilibrium Swelling Kinetics of Superabsorbent Nanocomposite}

Figures 7(a)-(c) show the swelling behavior of guar gum-g-acrylic acid in various $\mathrm{pH}$ buffer solutions. The 


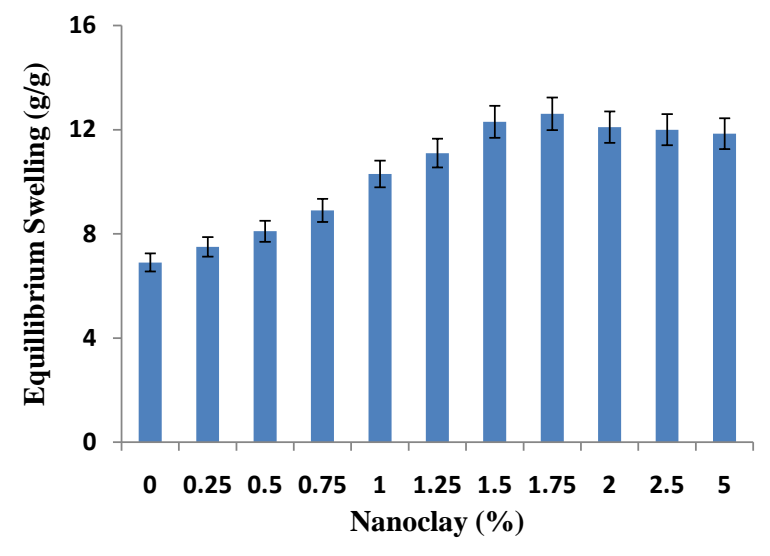

Figure 6. Effect of nanoclay on swelling characteristics.
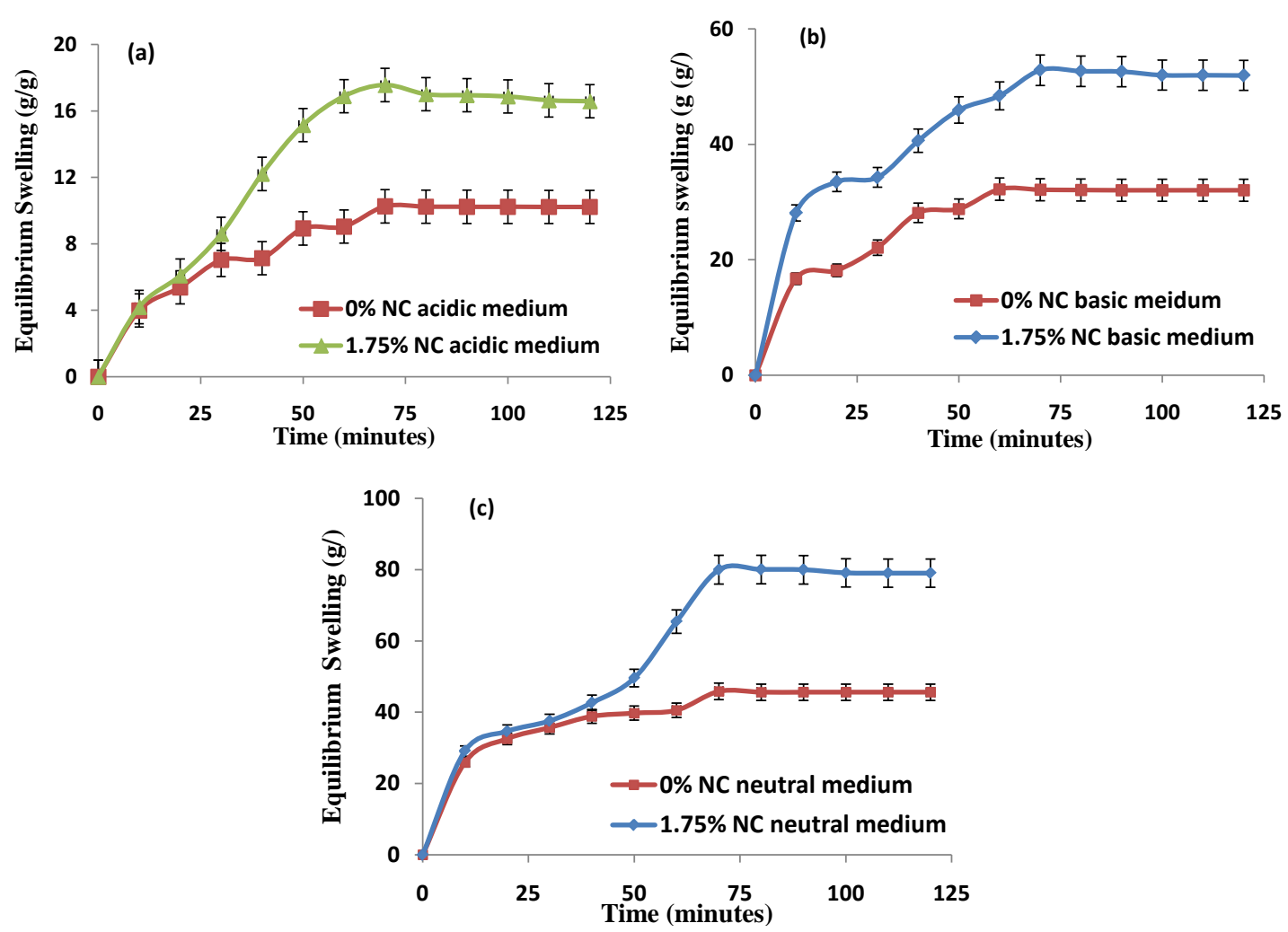

Figure 7. Swelling characteristics in (a) acidic (b) basic and (c) neutral medium.

swelling is lowest in acidic medium and highest in neutral medium. The hydrogen bonding interactions between $-\mathrm{OH}$ and $-\mathrm{COOH}$ led to increase in physical crosslinking and this in turn hindered swelling of the superabsorbent. As the $\mathrm{pH}$ increased beyond the acidic media range, the hydrogen bonding interactions are weakened leading to an increase in negatively charged - $\mathrm{COO}$ groups causing repulsion of polymer chains. Hence, this allows diffusion of water molecules in the network leading to an increase in swelling properties [40]. The addition of $1.75 \%$ NC showed a similar trend in various $\mathrm{pH}$ mediums although the magnitude is higher. The nanoclay enhanced the holding capacity of water due to increased surface area as reported by Wang et al. [37]

\subsection{Swelling Kinetics}

The swelling behavior with time is indicated in Figures 7(a)-(c), where the rate of swelling is high till 70 minutes and thereafter equilibrium is attained. The swelling kinetics of composites in three different buffer solu- 
tions can be evaluated using Schott's second order swelling kinetic model.

$$
\frac{t}{E S}=\frac{1}{K i}+\left(\frac{1}{E}\right) t
$$

where

$\boldsymbol{E}_{S}$ is the equilibrium swelling (g/g) at a given time $\boldsymbol{t}$ (minutes);

$\boldsymbol{K}_{\boldsymbol{i}}$ is the initial swelling rate constant $\left(\mathrm{g} \cdot \mathrm{g}^{-1} \cdot \mathrm{min}^{-1}\right)$;

$\boldsymbol{E}_{\boldsymbol{i}}$ is the theoretical equilibrium swelling $(\mathrm{g} / \mathrm{g})$.

The $t / E S$ versus $t$ plots of experimental data showed straight lines with linear correlation coefficient $\left(\mathrm{R}^{2}\right)>$ 0.95, indicating that Schott's swelling theoretical model is suitable for evaluating the kinetic swelling behavior of the composites. By fitting the experimental data with equation (3), the swelling kinetic parameters like the initial swelling rate constant $\left(K_{i}\right)$ and the theoretical equilibrium water absorption $(E)$, were calculated from the slope and intercept of the lines shown in Figure 8 and are listed in Table 1. Value of Ki for neutral buffer > basic buffer > acidic buffer indicates that the order of swelling capability in neutral medium is higher than that of basic and acidic medium.

\subsection{Dye Removal Studies}

\subsubsection{Effect of Nanoclay on Dye Removal}

Nanoclay has the positive effect on adsorption of dye solutions. Figure 9 indicates that for superabsorbent loaded with $1.75 \%$ NC shows a higher dye adsorption capacity (of $25.2 \%$ than the control sample) for an initial dye concentration of $30 \mathrm{mg} / \mathrm{l}$. The reason for this behavior is similar as explained earlier, nanoclay has active $-\mathrm{OH}$ group on its surface which increases the porous surface area and thus dye adsorption capacity increases [41].

\subsubsection{Effect of Contact Time on Adsorption Capacity}

Contact time between superabsorbent composites and dye solutions is an important factor on adsorption capacity. Figure 10 indicates variation of adsorption capacity with contact time for different dye concentrations (10 mg/l,

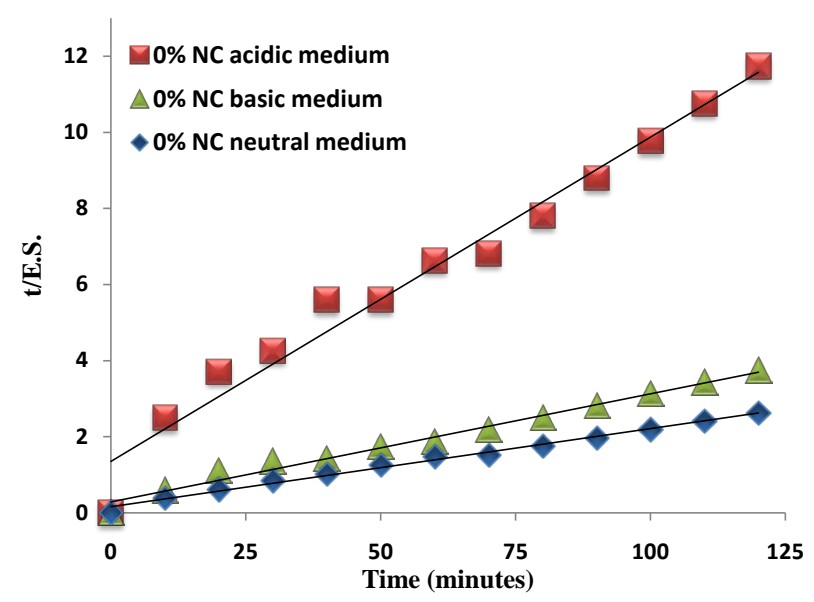

Figure 8. Schott's model for pseudo second order at 3 different $\mathrm{pH}$ mediums.

Table 1. Variation of swelling kinetic parameter of Schott's kinetic model in different buffer solutions.

\begin{tabular}{cccc}
\hline Buffer solution & $K_{i}$ & $\mathrm{E}$ & $<\mathrm{R}^{2}>$ \\
\hline Acidic & 0.741 & 11.764 & 0.972 \\
Basic & 3.508 & 35.714 & 0.984 \\
Neutral & 6.25 & 50 & 0.992 \\
\hline
\end{tabular}



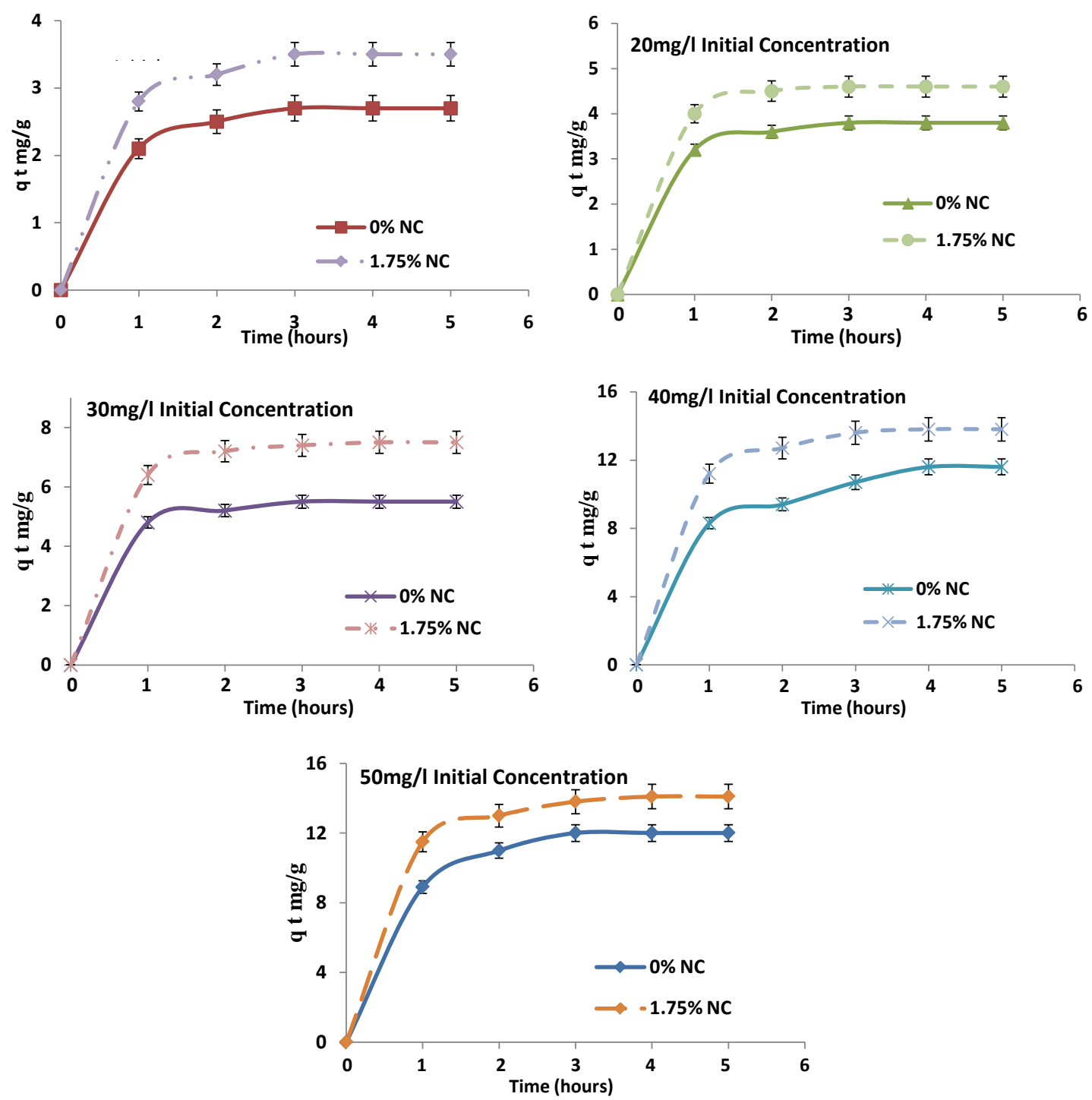

Figure 9. Effect on dye absorption capacity for guar gum based superabsorbent with and without nanoclay for varied initial concentration of crystal violet dye.

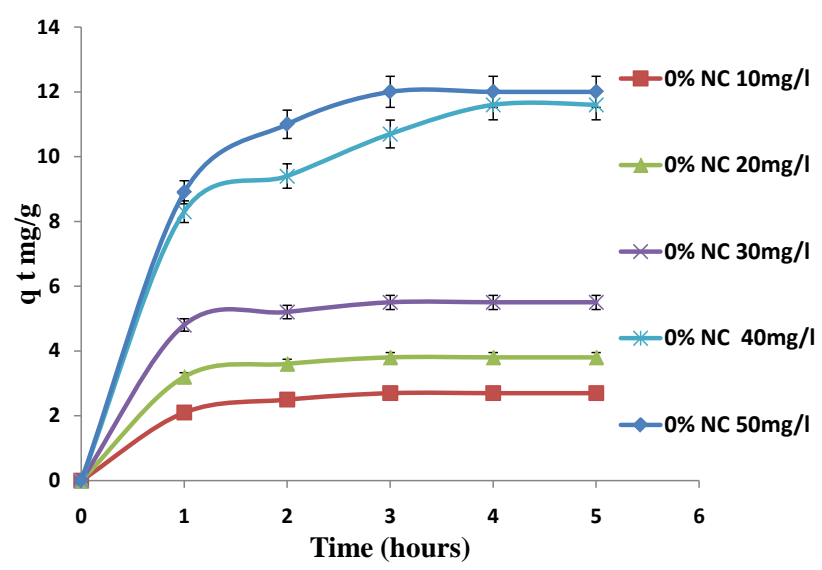

Figure 10. Variation of dye adsorption capacity of superabsorbent (without nanoclay) for different initial dye concentration w.r.t contact time. 
Table 2. Variation of dye adsorption kinetic parameters using pseudo second order model.

\begin{tabular}{cccc}
\hline Dye concentration $(\mathrm{mg} / \mathrm{l})$ & $\mathrm{K}$ ( $\left(\mathrm{g} \mathrm{mg}^{-1}\right.$ hour $\left.^{-1}\right)$ & $\mathrm{mg} / \mathrm{g})$ & $<.78$ \\
10 & 18.52 & 3.87 & 0.996 \\
20 & 40 & 5.62 & 0.998 \\
30 & 66.66 & 12.19 & 0.998 \\
40 & 41.66 & 12.50 & 0.987 \\
50 & 71.43 & 0.994 \\
\hline
\end{tabular}

$20 \mathrm{mg} / \mathrm{l}, 30 \mathrm{mg} / \mathrm{l}, 40 \mathrm{mg} / \mathrm{l}$ and $50 \mathrm{mg} / \mathrm{l})$. It is observed that dye adsorption capacity has increased till 3 hours of contact time, beyond which adsorption capacity reaches equilibrium. Also from the figure it can be observed that adsorption capacity will be higher at higher dye adsorption concentration. The reason for this behavior is adsorption capacity mainly depends on surface area of superabsorbent composites, at initial interval of time dye adsorption will be higher due to large surface area. Similar analyses have been reported by Wang et al. in case of methyl violet removal [41].

\subsubsection{Dye Adsorption Kinetics}

In order to investigate the dye adsorption mechanism pseudo second order model fits the best to experimental data like concentration of dye and adsorption capacity. The equation for pseudo-second order reaction is as follows,

$$
\frac{t}{q_{t}}=\frac{1}{K_{i}}+\left(\frac{1}{q}\right) t
$$

where

$\boldsymbol{q}_{\boldsymbol{t}}$ is the dye adsorption capacity (mg/g) at a given time $\boldsymbol{t}$ (hours);

$\boldsymbol{k}_{\boldsymbol{i}}$ is the initial dye adsorption rate constant $\left(\mathrm{g} \cdot \mathrm{mg}^{-1} \cdot\right.$ hour $\left.^{-1}\right)$;

$\boldsymbol{q}$ is the theoretical dye adsorption capacity (mg/g).

Plot of $t / q_{t}$ vs $t$ for different dye concentrations gives straight line with linear correlation $\left(\mathrm{R}^{2}\right)>0.98$, indicates that Schott's pseudo second order model fits best for the obtained experimental data. The values of initial dye adsorption rate constant $\left(K_{i}\right)$ and theoretical dye adsorption capacity $(q)$ can be determined using intercept and slope, and are tabulated in Table 2 . Initial dye adsorption rate constant $K_{i}$ values is in the order $50 \mathrm{mg} / \mathrm{l}>40$ $\mathrm{mg} / \mathrm{l}>30 \mathrm{mg} / \mathrm{l}>20 \mathrm{mg} / \mathrm{l}>10 \mathrm{mg} / \mathrm{l}$ which indicates that higher the initial dye concentration higher is the dye adsorption rate.

\section{Conclusion}

Superabsorbent nanocomposites based on acrylic acid grafted guar gum and silane modified nanoclay of varied quantitates have been synthesized via microwave irradiation. The reaction parameters for the grafting have been optimized. The addition of modified nanoclay enhanced swelling properties in various $\mathrm{pH}$ mediums ranging from acidic, neutral and alkaline buffers. The optimal nanoclay content has been found to be $1.75 \%$ w.r.t maximum swelling. Silane groups on nanoclay interacted effectively with the carboxylic and hydroxyl groups of grafted guar gum leading to exfoliation of nanoclay as seen in XRD diffractograms. The swelling kinetics was found to obey Schott's model with $\left\langle\mathrm{R}^{2}>\right.$ values above 0.97 . The crystal violet dye absorption increases with increases in initial dye concentration. The dye absorption was found to follow pseudo second order kinetics with $<\mathrm{R}^{2}>$ values above 0.99 . Addition of $1.75 \%$ nanoclay enhanced the dye absorption capability as compared to the control sample without nanoclay. The synthesized grafted natural gum superabsorbent nanocomposites can be used for the removal of toxic dyes from various contaminated water bodies. It can also be used to improve water retention and effective use of water resources in agriculture.

\section{References}

[1] Tiwari, A. and Prabaharan, M. (2010) An Amphiphilic Nanocarrier Based on Guar Gum-Graft-Poly(epsilon-caprolactone) for Potential Drug-Delivery Applications. Journal of Biomaterials Science, 21, 937-949. 
http://dx.doi.org/10.1163/156856209X452278

[2] Sharma, K., Kumar, V., Kaith, B.S., Som, S., Kumar, V., Pandey, A., Kalia, S. and Swart, H.C. (2015) Synthesis of Biodegradable Gum Ghatti Based Poly(methacrylic acid-aniline) Conducting IPN Hydrogel for Controlled Release of Amoxicillin Trihydrate. Industrial \& Engineering Chemistry Research, 54, 1982-1991. http://dx.doi.org/10.1021/ie5044743

[3] Sharma, K., Kumar, V., Kaith, B.S., Som, S., Kumar, V., Pandey, A., Kalia, S. and Swart, H.C. (2015) Evaluation of a Conducting Interpenetrating Network Based on Gum Ghatti-G-Poly(acrylic acid-aniline) as a Colon-Specific Delivery System for Amoxicillin Trihydrate and Paracetamol. New Journal of Chemistry, 39, 3021-3034. http://dx.doi.org/10.1039/C4NJ01982B

[4] Jassal, M. (2011) Design and Production Techniques for Hygiene Textiles. In: McCarthy, B.J., Ed., Textiles for Hygiene and Infection Control, Woodhead Publishing Ltd., Cambridge, 3-13.

[5] Benedetti, M. (2011) Biodegradable Hygiene Products, In: McCarthy, B.J., Ed., Textiles for Hygiene and Infection Control, Woodhead Publishing Ltd., Cambridge, 68-84.

[6] Singh, V.K., Banerjee, I., Agarwal, T., Pramanik, K., Bhattacharya, M.K. and Pal, K. (2014) Guar Gum and Sesame Oil Based Novel Bigels for Controlled Drug Delivery. Colloids and Surfaces B: Biointerfaces, 123, 582-592. http://dx.doi.org/10.1016/j.colsurfb.2014.09.056

[7] Finley, J,W., Soto-Vaca, A., Heimbach, J., Rao, T., Juneja, L.R., Slavin, J. and Fahey, G.C. (2013) Safety Assessment and Caloric Value of Partially Hydrolyzed Guar Gum. Journal of Agricultural and Food Chemistry, 61, 1756-1771. http://dx.doi.org/10.1021/jf304910k

[8] Guilherme, M.R., Aouada, F.A., Fajardo, A.R., Martins, A.F., Paulino, A.T., Davi, M.F.T., Rubira, A.F. and Muniz, E.C. (2015) Superabsorbent Hydrogels Based on Polysaccharides for Application in Agriculture as Soil Conditioner and Nutrient Carrier: A Review. European Polymer Journal, 72, 365-385.

http://dx.doi.org/10.1016/j.eurpolymj.2015.04.017

[9] Sharma, K., Kaith, B.S., Kumar, V., Kalia, S., Kumar, V., Som, S. and Swart, H.C. (2014) Gum Ghatti Based Novel Electrically Conductive Biomaterials: A Study of Conductivity and Surface Morphology. eXPRESS Polymer Letters, 8, 267-281. http://dx.doi.org/10.3144/expresspolymlett.2014.30

[10] Sharma, K., Kaith, B.S., Kumar, V., Kalia, S., Kumar, V., Som, S. and Swart, H.C. (2015) Synthesis, Characterization and Water Retention Study of Biodegradable Gum Ghatti-Poly(acrylic acid-aniline) Hydrogels. Polymer Degradation and Stability, 111, 20-31. http://dx.doi.org/10.1016/j.polymdegradstab.2014.10.012

[11] Sharma, K., Kaith, B.S., Kumar, V., Kalia, S., Kumar, V. and Swart, H.C. (2014) Water Retention and Dye Adsorption Behavior of Gg-cl-poly(acrylic acid-aniline) Based Conductive Hydrogels. Geoderma, 232-234, 45-55. http://dx.doi.org/10.1016/j.geoderma.2014.04.035

[12] Dharela, R., Raj, L. and Chauhan, G.S. (2012) Synthesis, Characterization, and Swelling Studies of Guar Gum-Based pH, Temperature, and Salt Responsive Hydrogels. Journal of Applied Polymer Science, 126, E259-E264. http://dx.doi.org/10.1002/app.36983

[13] Prabaharan, M. (2011) Prospective of Guar Gum and Its Derivatives as Controlled Drug Delivery Systems. International Journal of Biological Macromolecules, 49, 117-124. http://dx.doi.org/10.1016/j.ijbiomac.2011.04.022

[14] Singh, V., Kumari, P.L., Tiwari, A. and Sharma, A.K. (2007) Alumina Supported Synthesis of Cassia marginata Gum-g-poly(acrylonitrile) under Microwave Irradiation. Polymers for Advanced Technologies, 18, 379-385. http://dx.doi.org/10.1002/pat.899

[15] Singh, V. and Tiwari, A. (2008) Microwave-Accelerated Methylation of Starch. Carbohydrate Research, 43, $151-154$. http://dx.doi.org/10.1016/j.carres.2007.09.006

[16] Singh, V., Srivastava, A. and Tiwari, A. (2009) Structural Elucidation, Modification and Characterization of Seed Gum from Cassia javahikai Seeds: A Non-Traditional Source of Industrial Gums. International Journal of Biological Macromolecules, 45, 293-297. http://dx.doi.org/10.1016/j.ijbiomac.2009.06.007

[17] Singha, V., Kumara, P. and Sanghi, R. (2012) Use of Microwave Irradiation in the Grafting Modification of Polysaccharides-A Review. Progress in Polymer Science, 37, 340-364. http://dx.doi.org/10.1016/j.progpolymsci.2011.07.005

[18] Sosnika, A., Gotelli, G. and Abraham, G.A. (2011) Microwave-Assisted Polymer Synthesis (MAPS) as a Tool in Biomaterials Science: How New and How Powerful. Progress in Polymer Science, 36, 1050-1078. http://dx.doi.org/10.1016/j.progpolymsci.2010.12.001

[19] Wang, W. and Wang, A. (2009) Synthesis and Swelling Properties of Guar Gum-g-poly(sodium acrylate)/Na-Montmorillonite Superabsorbent Nanocomposite. Journal of Composite Materials, 23, 2805-2819. http://dx.doi.org/10.1177/0021998309345319

[20] Kabiri, K., Omidian, H., Zohuriaan-Mehr, M.J. and Doroudiani, S. (2011) Superabsorbent Hydrogel Composites and Nanocomposites: A Review. Polymer Composites, 32, 277-289. http://dx.doi.org/10.1002/pc.21046 
[21] Yan, L., Chang, P.R., Zheng, P. and Ma, X. (2012) Characterization of Magnetic Guar Gum-Grafted Carbon Nanotubes and the Adsorption of the Dyes. Carbohydrate Polymers, 87, 1919-1924. http://dx.doi.org/10.1016/j.carbpol.2011.09.086

[22] Ghorai, S., Sarkar, A.K., Panda, A.B. and Pal, S. (2013) Effective Removal of Congo Red Dye from Aqueous Solution Using Modified Xanthan Gum/Silica Hybrid Nanocomposite as Adsorbent. Bioresource Technology, 144, 485-491. http://dx.doi.org/10.1016/j.biortech.2013.06.108

[23] Mahdavinia, G.H. and Zhalebaghy, R. (2012) Removal Kinetic of Cationic Dye Using Poly(sodium acrylate)-Carrageenan/Na-Montmorillonite Nanocomposite Superabsorbents. Journal of Materials and Environmental Science, 3 , 895-906.

[24] Taunk, K. and Behari, K. (2006) Graft Copolymerization of Acrylic Acid onto Guar Gum. Journal of Applied Polymer Science, 77, 39-44. http://dx.doi.org/10.1002/(SICI)1097-4628(20000705)77:1<39::AID-APP6>3.0.CO;2-Z

[25] Reddy, T.T., Reddy, N.S. and Tammishetti, S. (2003) Synthesis and Characterization of Guar Gum-Graft-Polyacrylonitrile. Polymers for Advanced Technologies, 14, 663-668. http://dx.doi.org/10.1002/pat.372

[26] Kumar, A., Aerry, S., Saxena, A., De, A. and Mozumdar, S. (2012) Copper Nanoparticulates in Guar-Gum: A Recyclable Catalytic System for the Huisgen [3 + 2]-Cycloaddition of Azides and Alkynes without Additives under Ambient Conditions. Green Chemistry, 14, 1298-1301. http://dx.doi.org/10.1039/c2gc35070j

[27] Liu, Y., Chen, H., Zhang, J.P. and Wang, A.Q. (2013) Effect of Number of Grindings of Attapulgite on Enhanced Swelling Properties of the Superabsorbent Nanocomposites. Journal of Composite Materials, 47, 969-978. http://dx.doi.org/10.1177/0021998312443398

[28] Giri, A., Bhunia, T., Mishra, S.R., Goswami, L., Panda, A., Pal, S. and Bandyopadhyay, A. (2013) Acrylic Acid Grafted Guargum-Nanosilica Membranes for Transdermal Diclofenac Delivery. Carbohydrate Polymers, 91, $492-501$. http://dx.doi.org/10.1016/j.carbpol.2012.08.035

[29] Amuda, O.S., Olayiwola, A.O., Alade, A.O., Farombi, A.G. and Adebisi, S.A. (2014) Adsorption of Methylene Blue from Aqueous Solution Using Steam-Activated Carbon Produced from Lantana camara Stem. Journal of Environmental Protection, 5, 1352-1363. http://dx.doi.org/10.4236/jep.2014.513129

[30] Bhanu, P. and Chauhan, S. (2011) Hybrid Nanomaterials. Wiley, Hoboken.

[31] Sharma, K., Kaith, B.S., Kumar, V., Kumar, V., Som, S., Kalia, S. and Swart, H.C. (2013) Synthesis and Properties of Poly(acrylamide-aniline)-Grafted Gum Ghatti Based Nanospikes. RSC Advances, 3, 25830-25839. http://dx.doi.org/10.1039/c3ra44809f

[32] Wang, W., Zhang, J. and Wang, A. (2009) Preparation and Swelling Properties of Superabsorbent Nanocomposites Based on Natural Guar Gum and Organo-Vermiculite. Applied Clay Science, 46, 21-26. http://dx.doi.org/10.1016/j.clay.2009.07.001

[33] Singha, A.S. and Rana, A.K. (2011) Kinetics Study on Acrylic Acid (AAc) Graft Copolymerized Cannabis Indica Fibre. Iranian Polymer Journal, 20, 913-919.

[34] Kalia, S., Kumar, A. and Kaith, B.S. (2011) Sunn Hemp Cellulose Graft Copolymers Polyhydroxybutyrate Composites: Morphological and Mechanical Studies. Advanced Materials Letters, 2, 17-25.

http://dx.doi.org/10.5185/amlett.2010.6130

[35] Bardajee, G.R., Pourjavadi, A., Soleyman, R., Pourjavadi, A., Soleyman, R. and Ghavami, S. (2011) Salep-gPoly(sodium acrylate)/Alumina as an Environmental-Sensitive Biopolymer Superabsorbent Composite: Synthesis and Investigation of Its Swelling Behavior. Advances in Polymer Technology, 31, 41-51. http://dx.doi.org/10.1002/adv.20233

[36] Chen, Y., Liu, Y.-F., Tan, H.-M. and Jiang, J.-X. (2008) Synthesis and Characterization of a Novel Superabsorbent Polymer of N,O-Carboxymethyl Chitosan Graft Copolymerized with Vinyl Monomers. Carbohydrate Polymers, 72, 287-292.

[37] Wang, Y., Wang, W., Shi, X. and Wang, A. (2013) A Superabsorbent Nanocomposite Based on Sodium Alginate and Illite/Smectite Mixed-Layer Clay. Journal of Applied Polymer Science, 130, 161-167. http://dx.doi.org/10.1002/app.39141

[38] Likhitha, M., Sailaja, R.R.N., Priyambika, V.S. and Ravibabu, M.V. (2014) Microwave Assisted Synthesis of Guar Gum Grafted Sodium Acrylate/Cloisite Superabsorbent Nanocomposites: Reaction Parameters and Swelling Characteristics. International Journal of Biological Macromolecules, 65, 500-508. http://dx.doi.org/10.1016/j.ijbiomac.2014.02.008

[39] Zhang, Y., Gu, Q., Yin, J., Wang, Z. and He, P. (2014) Effect of Organic Montmorillonite Type on the Swelling Behavior of Superabsorbent Nanocomposites. Advances in Polymer Technology, 33, Article ID: 21400.

[40] Wang, W. and Wang, A. (2010) Preparation, Swelling and Water-Retention Properties of Crosslinked Superabsorbent Hydrogels Based on Guar Gum. Advanced Materials Research, 96, 177-182. 
http://dx.doi.org/10.4028/www.scientific.net/AMR.96.177

[41] Wang, Y., Zeng, L., Ren, X., Song, H. and Wang, A. (2010) Removal of Methyl Violet from Aqueous Solutions Using Poly(acrylic acid-co-acrylamide)/Attapulgite Composite. Journal of Environmental Sciences, 1, 7-14.

http://dx.doi.org/10.1016/S1001-0742(09)60068-1 